Mr Milovan Unković,

dipl. inž.

Tehnički opitni centar KoV,

Poligon Luštica-Radovići,

\section{FIBER-OPTIČKI ŽIROKOMPAS}

UDC: $629.1 .054:[621.39: 535.37]$

Rezime:

U radu je opisan princip rada, konstrukcija i karakteristike brodskog žirokompasa. Prikazane su principijelne razlike u radu klasičnog i fiber-optičkog žirokompasa. Razmotrene su i karakteristike fiber-optičkog žirokompasa u skladu sa standardom ISO 8728 i izvršeno je poređenje sa karakteristikama klasičnih žirokompasa.

Ključne reči: žirokompas, fiber-optički žirokompas, Sanjakov efekat, karakteristike žirokompasa.

\title{
FIBER-OPTIC GYROCOMPASS
}

\section{Summary:}

This work describes the operation principle, construction and characteristics of a ship fiber-optic gyrocompass. Main differences in the operation of the gyrocompass and a classical one are considered as well as the fiber-optic gyrocompass characteristics, given according to ISO 8728 standard and compared to the characteristics of their classical counterparts.

Key words: gyrocompass, fiber-optic gyrocompass, Sagnac effect, gyrocompass characteristics.

\section{Uvod}

Fiber-optički žirokompasi su elektronski žirokompasi bez rotirajućih mehaničkih komponenata. Osnovni princip rada ovih kompasa zasniva se na nepromjenljivosti brzine svjetlosti i Sanjakovom efektu. Fiber-optički kalem koristi se kao vrlo osjetljivi senzor koji mjeri brzinu okretanja Zemlje. Za određivanje pravca sjevera koriste se tri fiber-optička kalema (žiroskopa) i dva elektronska senzora nivoa. Signali sa žiroskopa u kombinaciji sa signalima senzora nivoa, uz korištenje složnih Kalmanovih filtera, određuju smjer rotacije Zemlje. Iz ovog podatka nalazi se geografski sjever, a odatle se računa kurs broda, uglovi ljulja- nja i posrtanja, kao i brzine okretanja oko sve tri ose. Fiber-optički žirokompas se, takođe, koristi kao senzor za stabilizaciju ne samo trgovačkih brodova već i hidroglisera i katamarana. Vrlo visoka dinamička tačnost i odsustvo greške brzine bitno poboljšavaju sigurnost plovidbe svih brodova, posebno pri velikim brzinama na visokim geografskim širinama $u$ toku manevara.

Sve ovo daje mogućnost da se fiber-optički žirokompas prvenstveno može koristiti kod ratnih brodova za potrebe navigacije i stabilizacije. Nije naodmet napomenuti da je firma C.PLATH, kao prvi proizvođač fiber-optičkih žirokompasa, 1997. godine dobila godišnju nagradu za inovaciju u pomorstvu. 


\section{Princip rada - Sanjakov efekat}

Dok je princip rada mehaničkog žirokompasa baziran na momentu inercije brzog rotirajućeg diska, fiber-optički žirokompas koristi Sanjakov (Sagnac) efekat [1], otkriven 1913. godine. On se može objasniti na sljedeći način: u kružni put svjetlosti poluprečnika $r$ svjetlosni talas ulazi u tački P (slika 1). Ovdje se svjetlosni talas dijeli u dva talasa koji se kreću u suprotnim smjerovima kroz prsten: jedan $\mathrm{u}$ smjeru kazaljke na satu (clockwise - cw), a drugi suprotno (counterclockwise - ccw). Kako se smatra da je put svjetlosti idealan, on je prema tome isti za oba svjetlosna talasa koji se kreću u različitim smjerovima kroz prsten. U skladu s tim, oba talasa svjetlosti će se istovremeno vratiti u početnu tačku P. U ovoj tački će se talasi spojiti i napustiti prsten. Vrijeme prolaska svakog od talasa kroz prsten može se mjeriti vrlo osjetljivim detektorom.

Što se događa kada put svjetlosti (odnosno prsten) rotira dok se svjetlosni talas kreće kroz prsten? Pretpostavimo da put svjetlosti rotira u smjeru kazaljke na satu. Tačka ulaza i izlaza P će se kretati u

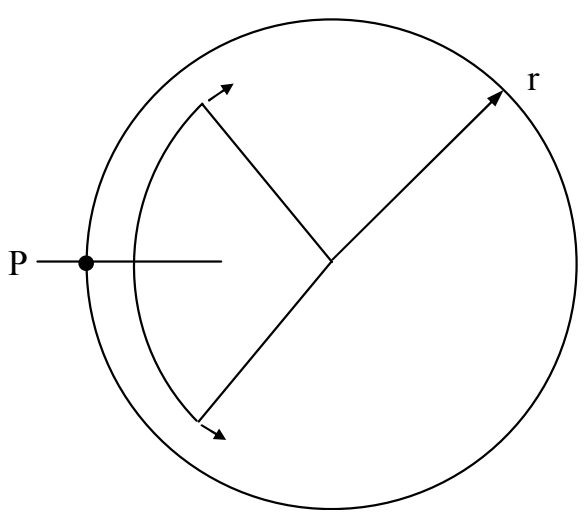

Sl. 1 - Put svjetlosti kroz nepokretni prsten

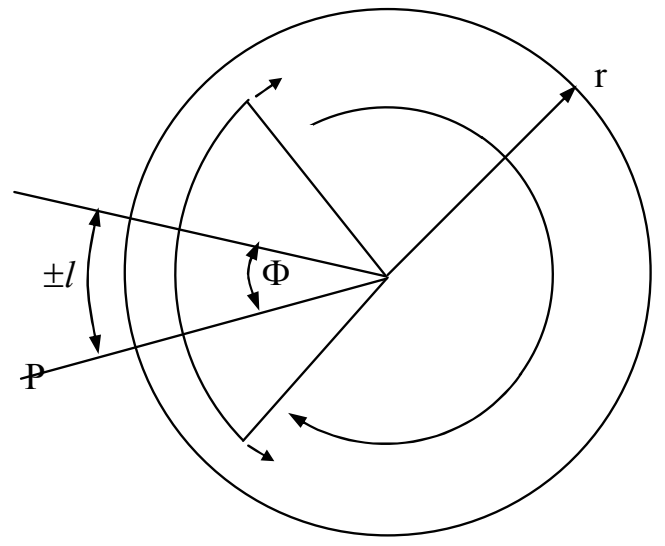

Sl. 2 - Put svjetlosti kroz krug koji rotira ugaonom brzinom $\Omega$

smjeru svjetlosnog talasa koji se kreće suprotno od kazaljke na satu, odnosno u suprotnom smjeru od talasa koji se kreće u smjeru kazaljke na satu. Jedan talas će se kretati dužim putem da bi došao u tačku P, dok će drugi talas prevaliti manji put. Put svjetlosti (prsten) poluprečnika $r$ ima obim $L=2 \pi$ r. Vrijeme za koje se pređe ovaj put L iznosi:

$T=L / c=\frac{2 \pi r}{c}$

gdje je c - brzina svjetlosti.

$\mathrm{U}$ toku vremena $\mathrm{T}$ put svjetlosti rotira ugaonom brzinom $\Omega$ za ugao $\Phi=\Omega$ T . Skraćivanje jednog puta svjetlosti za $1=r \Phi$ može se napisati kao:

$L_{-}=L-l$

Povećanje drugog puta svjetlosti je:

$L_{+}=L+l$

Ukupna razlika u putu svjetlosti je:

$\Delta L=L_{+}-L_{-}=2 \cdot l=2 r \Phi=2 r \Omega T=\frac{2 \Omega r L}{c}(4)$ 
Ako se ova razlika podijeli sa talasnom dužinom svjetlosnog talasa, dobija se razlika u jedinicama talasne dužine. Smatrajući da je talasna dužina $\lambda$ ekvivalentna faznom uglu od $2 \pi$, razlika puta se može izraziti kao fazni pomjeraj između dva svjetlosna talasa:

$\Phi_{S}=2 \pi \Delta L / \lambda$

Ovaj fazni pomjeraj zove se Sanjakova faza. To znači da rotacija dva svjetlosna talasa, koji se kreću u suprotnim smjerovima, daje fazni pomjeraj. Ako se izraz (4) uvrsti u izraz (5), dobija se relacija (6) koja daje vezu između Sanjakove faze i ugaone brzine rotiranja faze svjetlosti:

$\Phi_{S}=\frac{4 \pi r L}{\lambda c} \Omega$

Konstantni faktor ispred $\Omega$ predstavlja faktor skaliranja. On određuje sa kojom osjetljivošću interferometar pretvara ugaonu brzinu u fazni pomjeraj. Jednakost, takođe, pokazuje da osjetljivost zavisi od geometrijskih osobina fiberskog kalema. Osjetljivost raste sa povećavanjem prečnika kalema i povećanjem dužine optičkog fibera.

Sanjakov interferometar, kako je upravo opisan, ima kosinusnu prenosnu funkciju [2]. To znači da se u slučaju nulte fazne razlike između signala $\mathrm{cw}$ i ccw, signali sabiraju i javlja se maksimalni intenzitet $I_{\max }$ (slika 3). Kada je fazna razlika između signala cw i ccw $\pi$, jačina superponiranog signala je minimalna $-\mathrm{u}$ idealnom slučaju jednaka je nuli (slika 4).

Kosinusna prenosna funkcija interferometra može se predstaviti izrazom:

$i=f\left(\Phi_{S}\right)=\left(I_{\max } / 2\right)\left[1+\cos \left(\Phi_{S}\right)\right]$

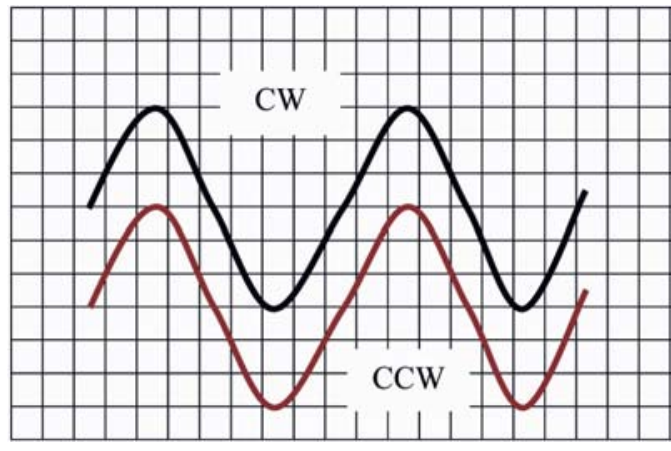

Sl. 3 - Slučaj kada je fazna razlika nulapojačanje

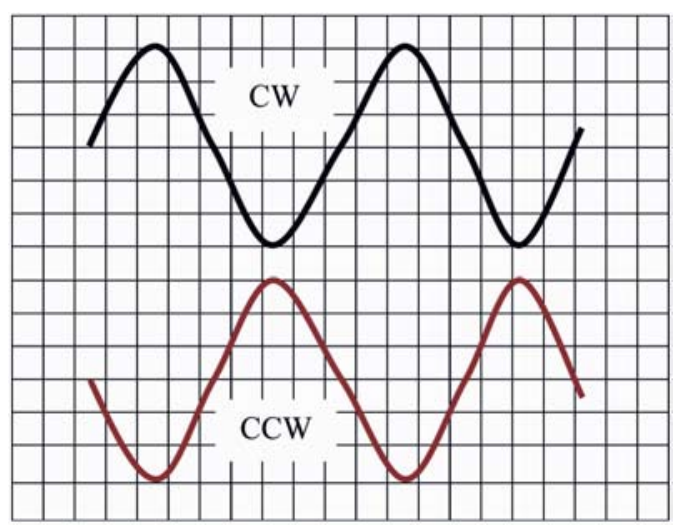

Sl. 4 - Slučaj kada postoji fazna razlika $\pi$-prigušenje

Simetrična kosinusna prenosna funkcija ima dva nedostatka (slika 5):

- osjetljivost oko nultog položaja (stanja mirovanja) vrlo je mala zbog horizontalnog nagiba tangente;

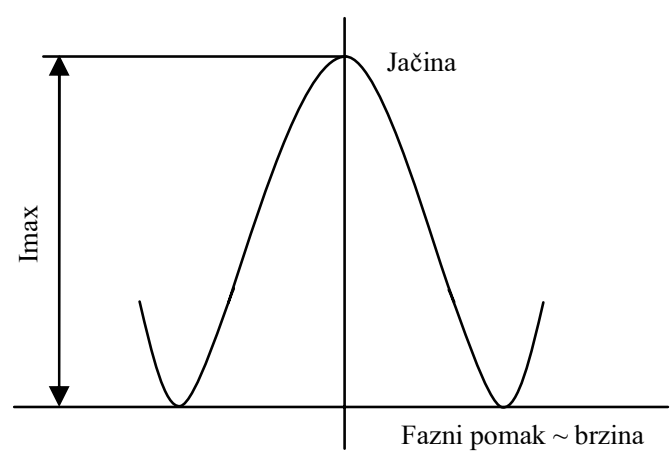

Sl. 5 - Simetrična kosinusna prenosna funkcija 
- bilo koja ulazna rotacija vodi ka smanjenju intenziteta I, a ne može se odrediti ni smjer rotacije.

Da bi se ovi nedostaci izbjegli, $u$ interferometar se uvodi fazni pomjerač koji daje fazni pomak od $+\pi / 2$ ili $-\pi / 2$. Ovaj vještački uvedeni fazni pomak pomjera radnu tačku na prenosnoj funkciji u njen linearni dio. Istovremeno se vrši i modulacija signalom čija je frekvencija ekvivalentna vremenu puta svjetlosnog talasa. Time se postiže dodatna DC stabilnost. Na slikama 6 i 7 prikazani su izlazni signali iz interferometra u slučaju kada nema rotacije i u slučaju kada ona postoji.

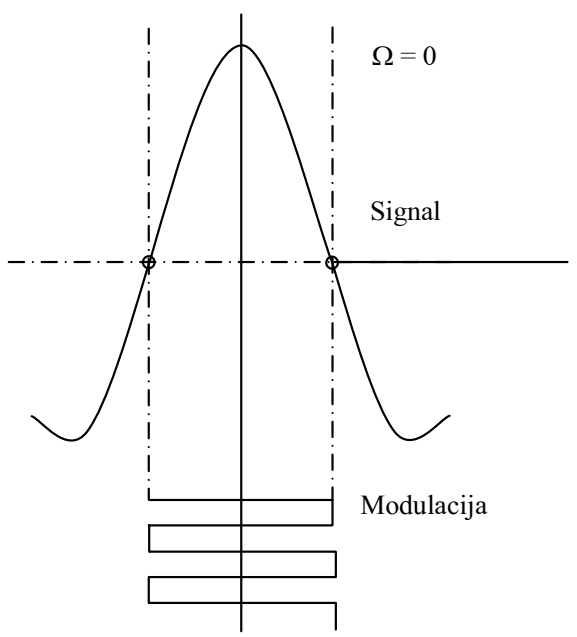

Sl. 6-Modulacija kada nema rotacije

Mjerenjem amplitude signala uz primjenu sinhrone demodulacije određuje se brzina rotacije. Razmještaj sa fazno osjetljivim ispravljačem (usmjeračem) daje signal čija je amplituda proporcionalna ugaonoj brzini. Za postizanje visoke linearnosti i ostvarivanje mjerenog opsega, koji može obrađivati fazni ugao $\Phi \geq \pi$, koristi se metod zatvorene petlje. $\mathrm{Na}$ fazni modulator dodaje se kompenza-

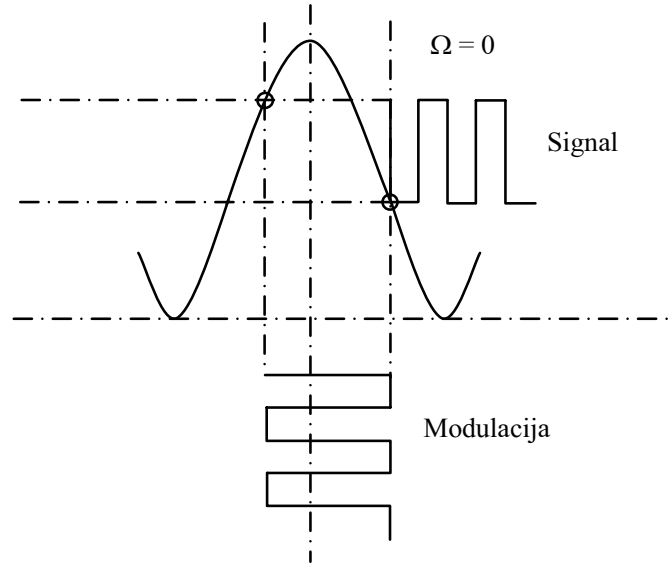

Sl. 7 - Modulacija kada postoji rotacija

cioni signal koji ima istu vrijednost, ali suprotan znak od Sanjakove faze. Sa idealnom kompenzacijom detektor mjeri nultu vrijednost amplitude. Kompenzacioni napon je direktno proporcionalan Sanjakovoj fazi.

Direktno računanje brzine rotacije iz amplitude modulisanog izlaznog signala ostvaruje se tehnikom otvorene petlje. Kosinusna prenosna funkcija uslovljava nelinearnost faktora skaliranja i ograničava izlaznu brzinu na prvi član periodične funkcije. Ako se izračunata brzina rotacije doda signalu faznog modulatora sa negativnim podznakom, doći će do kompenzacije Sanjakove faze. AC amplituda izlaznog signala se kontrolisano približava nuli. Ovaj metod kompenzacije zove se tehnika zatvorene petlje, a njena prednost je postizanje visoke linearnosti faktora skaliranja i mogućnost korišćenja neograničene ulazne brzine. Pomjerač faze je u interferometru postavljen asimetrično u fiberskoj petlji. U prenosnu funkciju (7) dodaju se dva člana:

$i=f\left(\Phi_{S}\right)=\left(I_{\max } / 2\right)\left[1+\cos \left(\Phi_{S}+\Phi(t)-\right.\right.$

$-\Phi(t+\tau))]$ 
gdje je:

$\Phi(\mathrm{t})$ - fazni pomak ccw talasa prije ulaska u petlju,

$\Phi(\mathrm{t}+\tau)$ - fazni pomak cw talasa nakon prolaska kroz petlju za vrijeme $\tau$.

U tehnici zatvorene petlje argument $\mathrm{u}$ prenosnoj kosinusnoj funkciji je konstantan:

$\Phi_{S}+\Phi(t)-\Phi(t+\tau)=$ const

$\Phi(t)-\Phi(t+\tau)=$ const $-\Phi_{S}$

Da bi se razlika faza na lijevoj strani jednakosti (10) držala konstantnom u vremenu potrebno ju je povećavati za iznos (const $-\Phi_{S}$ ) svakih $\tau$ sekundi (slika 8 ).

S obzirom na to da je period kosinusne funkcije $2 \pi$, digitalna rampa se resetuje ako vrijednost pređe $2 \pi$ (slika 9 ).

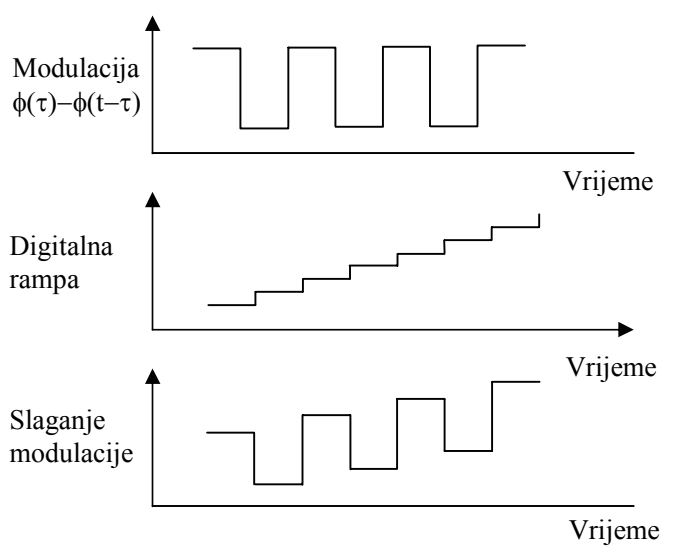

Sl. 8 - Rampa digitalne faze

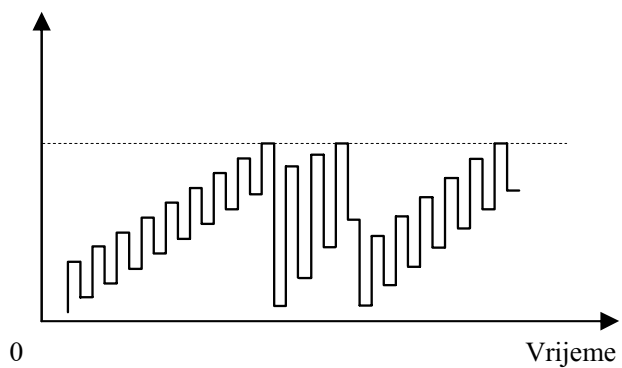

Sl. 9 - Resetovanje rampe digitalne faze

\section{Fiber-optički žiroskop}

U daljnjem tekstu biće opisane komponente fiber-optičkog žiroskopa, odnosno Sanjakovog interferometra, i njegove osnovne funkcije $[4,5]$ (slika 10).

Kao izvor svjetlosti koristi se superluminiscentna dioda (SLD) koja predstavlja modifikovanu formu poluprovodničkog lasera. Za razliku od lasera, SLD ne posjeduje optički rezonator. Tipične osobine SLD su: talasna dužina od $830 \mathrm{~nm}$, koherentna dužina $50 \mu \mathrm{m}$ i intenzitet 100 do $1000 \mu \mathrm{W}$. Emitovanje svjetlosnog talasa sa laserske i SLD diode prikazano je na slici 11.

Idealni kružni put svjetlosti je, u stvari, kalem optičkog fibera. Središte i košuljica (plašt) optičkog fibera najvećim se dijelom izrađuju od kvarcnog stakla, koje je okruženo plastičnim omotačem. Karakteristike provođenja svjetlosti bazirane su na potpunoj refleksiji svjetlosti od materijala koji mijenjaju upadne uglove. Da bi se obezbijedilo da svjetlosni put ima istu dužinu u oba smjera, koriste se takozvani monomodni ili jednomodni fiberi. Prečnik središnjeg dijela optičkog fibera je unutar opsega talasne dužine laserske svjetlosti. Da bi se održali isti putevi svjetlosti, optički fiber mora biti polarizaciono-održavajućeg tipa, ili alternativno svi efekti interferencije moraju biti poništeni dvostrukim prelamanjem. To se postiže potpunom depolarizacijom svjetlosti na jednom kraju puta, što je i glavni razvojni korak u proizvodnji fiber-optičkog žirokompasa. Standardne dimenzije monomodnog fibera su: prečnik središta 4 do $6 \mu \mathrm{m}$, prečnik košuljice 80 do $125 \mu \mathrm{m}$, prečnik omotača 65 do $250 \mu \mathrm{m}$. 

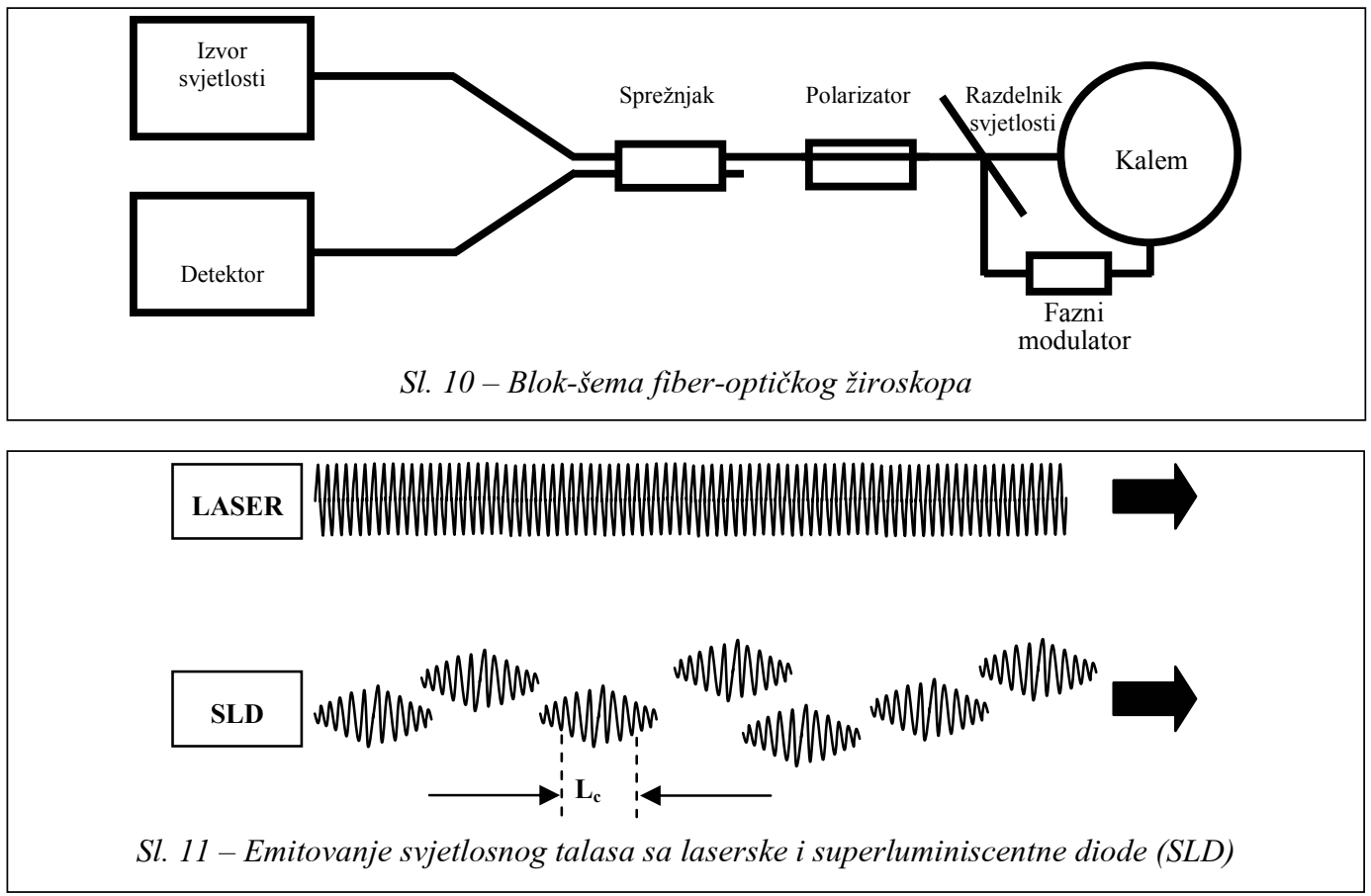

Osjetljivost interferometra raste sa povećanjem dužine fibera i prečnika $f i$ berskog kalema. Za primjenu kod žirokompasa optički fiber dužine $500 \mathrm{~m}$ namotan je na kalem prečnika $8 \mathrm{~cm}$.

Razdjelnik svjetlosnog snopa je integrisana optička komponenta. Monomodni talasovod je integrisan $\mathrm{u}$ litijumniobatnom kristalu $\left(\mathrm{LiNbO}_{3}\right)$ sa izvedbom na supstratu Y oblika (slika 12). Integrisano kolo ima ulaz i dva izlaza. Proizvodni proces nastajanja komponente naziva se „izmjena kaljenih protona“.
Razdjelnik snopa svjetlosti djeluje i kao polarizator, jer se talasovod proizveden izmjenom protona može polarisati samo u jednom smjeru.

Treća funkcija ovog kompleksnog integrisanog kola, pored funkcija razdjelnika snopa svjetlosti i polarizatora, je funkcija faznog modulatora. Pri tome se koriste elektrooptičke karakteristike $\mathrm{LiNbO}_{3}$ kristala, gdje se indeks prelamanja može mijenjati uticajem električnog polja. Na talasovod integrisane komponente priključene su elektrode (10 mm dužine na intervalima

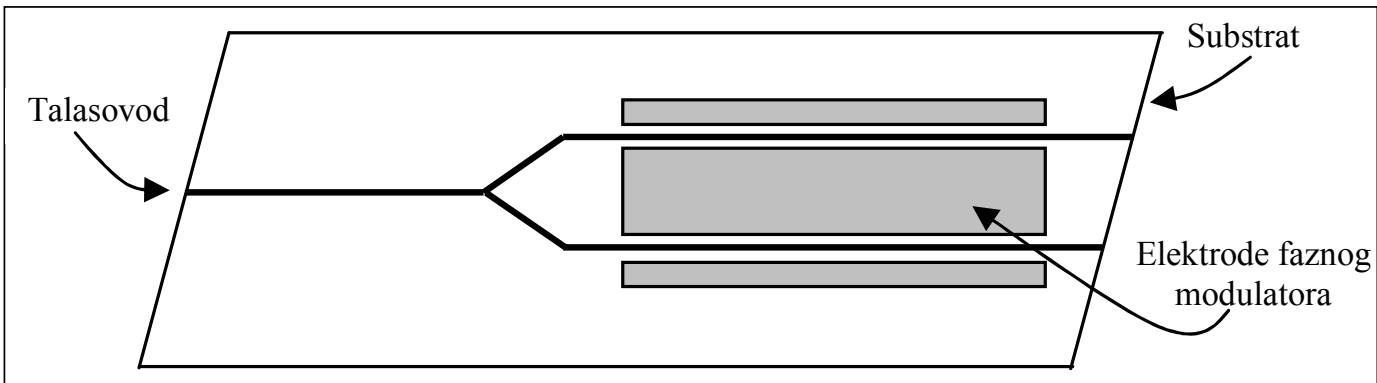

Sl. 12 - Višefunkcijsko integrisano logičko kolo (MIOC) 
10 do $20 \mu \mathrm{m})$. Niskim naponom postiže se fazni pomjeraj od $2 \pi$.

Svjetlost koja se vraća sa interferometra spregnuta je između izvora svjetlosti i razdjelnika i dolazi na detektor koji je osjetljiv na svjetlost. Sprežnjak sadrži dva fibera spojena zajedno, tako da polovina svjetlosti prelazi sa jednog na drugi fiber.

Svjetlost, dobijena preko sprežnjaka, pretvara se u električnu struju pomoću poluprovodničke diode osjetljive na svjetlost (fotodetektor) i koristi se $u$ funkciji zatvorene petlje. Električni signal sa fotodetektora pretpojačava se i pretvara u digitalni signal $u$ analogno-digitalnom pretvaraču. Ova ,informacija“ može se obrađivati u digitalnom računaru (digitalno procesiranje). U operaciji zatvorene petlje, obrada signala se izvodi za isti period vremena za koji se zahtijeva da putuje svjetlost kroz fiberski kalem. Za fiberski kalem dužine $500 \mathrm{~m}$, ovaj period je manji od $2 \mu \mathrm{s}$, a unutar tog perioda procesor signala mora izvršiti sve zahtijevane radnje.

\section{Kompletni sistem}

Inercijalna mjerna jedinica sastoji se od tri fiber-optička žiroskopa, osjetljiva na promjenu kursa, posrtanje i ljuljanje broda i dva senzora (detektora) nivoa. Uz inercijalnu mjernu jedinicu sistem sadrži: jedinicu za upravljanje i prikazivanje na displeju, interfejs i jedinicu napajanja. Arhitektura inercijalnog sistema prikazana je na slici 13 , a kompletna elektronika fiber-optičkog žirokompasa na slici 14.

Analogni i digitalni pokazivači (ponavljači) i drugi periferni uređaji napaja-

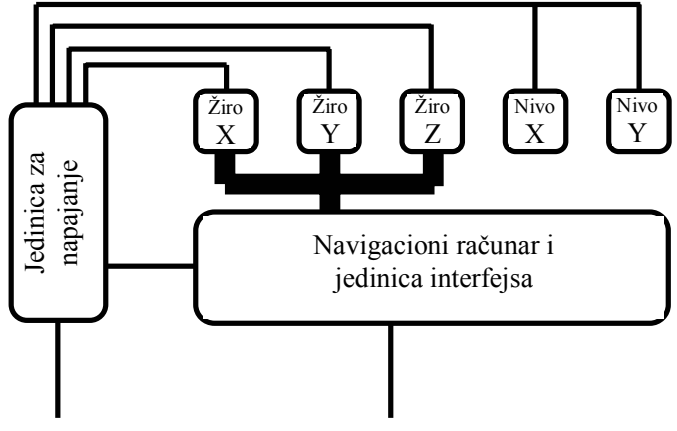

Sl. 13 - Arhitektura inercijalnog sistema

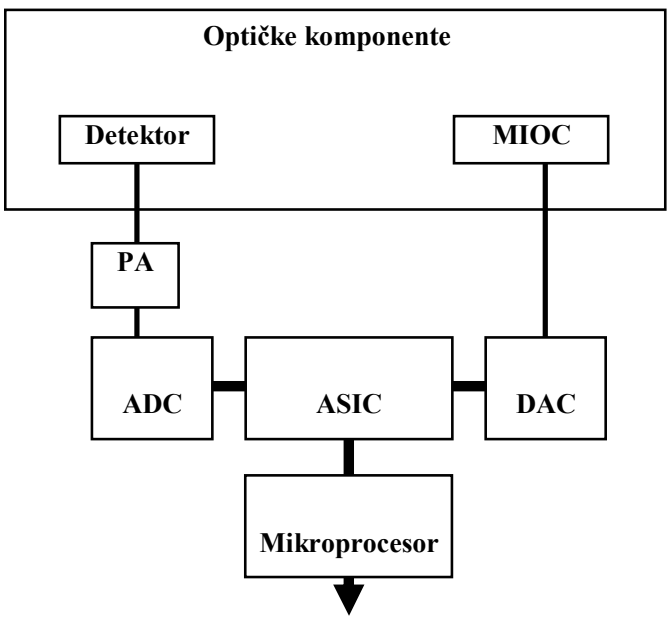

Sl. 14 - Elektronika fiber-optičkog žirokompasa: $P A$ - pretpojačavač, $A D C$ - analogno-digitalni pretvarač, $D A C$ - digitalno-analogni pretvarač, ASIC - integrisano kolo specijalne namene, MIOC - višefunkcionalno integrisano optičko kolo

ju se izlaznim podacima preko serijskog interfejsa. Sistemu je moguće dodati i drugi žirokompas - prenosni magnetni kompas (magnetska vrata).

\section{Poređenje rada klasičnog i fiber-optičkog žirokompasa}

Da bi se rad fiber-optičkog žirokompasa bolje razumeo korisno je izvršiti poređenje njegovog funkcionisanja sa radom konvencionalnih žirokompasa. 
Žirokompasi za svoj rad koriste dva prirodna fenomena: rotaciju i gravitaciju Zemlje, a ponašaju se u skladu sa dva zakona klasične mehanike: zakonom inercije i zakonom precesije. Osnovni princip na kojem se zasniva rad svih nemagnetnih kompasa je realizacija ravni koja se stalno pozicionira u prostoru. Princip traženja sjevera ostvaruje se izdvajanjem signala koji se generišu kao posljedica rotacije Zemlje. Oni se koriste da ravan postave $u$ horizontalan položaj, a referentnu osu (liniju) koja leži u toj ravni, i fiksno je podešena u početnom položaju, dovedu u pravac geografskog sjevera.

\section{Prostorno orjentisana ravan}

U klasičnom slučaju žirokugle, glavne ose dva žiroskopa, postavljene su pod određenim uglom jedna u odnosu na drugu (na primjer $90^{\circ}$ ). Ove ose formiraju ravan koja se stalno pozicionira u prostoru. Ugao između ove ravni i ravni koja je fiksno vezana za brod nije potpuno poznat. $\mathrm{Na}$ ovu fizički definisanu ravan dodaju se određene mehaničke komponente (na primjer referentno klatno, viskozni indikator nivoa ili akcelerometar). Kod konvencionalnih žirokompasa sa žirokuglom referentno klatno se realizuje tako što se centar gravitacije (težište) osjetljivog elementa spušta vertikalno u odnosu na tačku vješanja (geometrijski centar). $\mathrm{Na}$ taj način žirosfera postaje osjetljiva na ubrzanje i nagib (posljedice rotacije Zemlje), pa se automatski generiše obrtni moment oko horizontalne ose, što izaziva precesiju.

Kod fiber-optičkog žirokompasa prostorno orijentisana ravan nije definisana mehanički. Jedina ravan koja realno postoji je ravan fiksirana za brod na kojoj je žirokompas montiran. Na osnovu ugaonih brzina ravni koja je kruto vezana za brod oko sve tri ose (x, y i z) i pripadajućih uglova rotacije, kreira se virtuelna ravan čiji se položaj u odnosu na početni memoriše u procesnom računaru u obliku direkcionalne kosinusne matrice. Ova virtuelna ravan ne postoji u prostoru u bilo kakvoj mehaničkoj formi. Poznati su i stalno prisutni samo Ojlerovi uglovi oko kojih se okreće ravan vezana za brod, a preko ovih uglova kreira se i definiše virtuelna ravan, koja ne može sadržati bilo kakve dodate mehaničke elemente (slika 15).

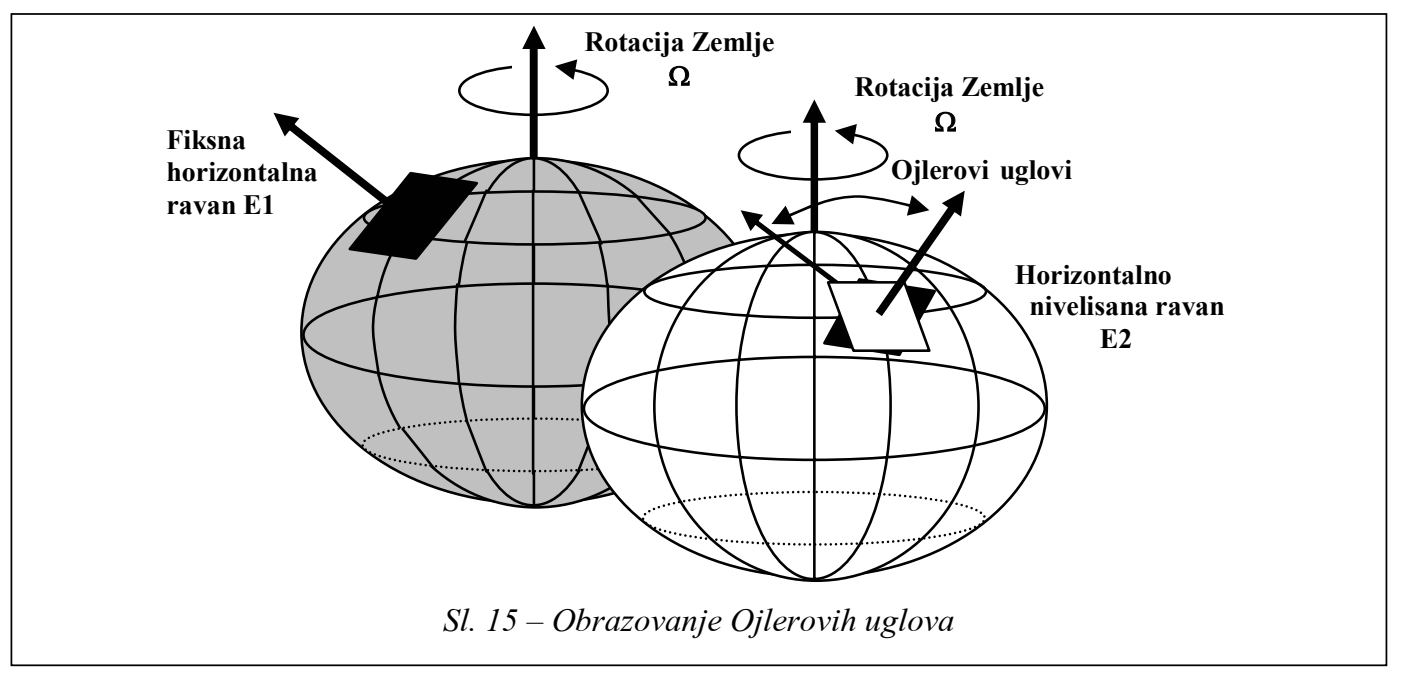




\section{Horizontalno nivelisanje}

Vertikalno premještanje centra gravitacije žirosfere uzrokuje nastanak efekta klatna. Ovakav način funkcionisanja osigurava da žirosfera, odnosno početna definisana prostorno orijentisana ravan, dolazi u horizontalan položaj kada centar gravitacije osjetljivog elementa leži direktno ispod tačke vješanja (na liniji koja spaja tačku vješanja i centar Zemlje). Zbog mehaničke konstrukcije klasičnog žirokompasa, proces horizontalnog nivelisanja orijentisane ravni nije jednostavan, a za potpunije objašnjenje koristi se komplikovani matematički aparat klasične mehanike.

Da bi se osigurala funkcija traženja sjevera, početna prostorno orijentisana ravan fiber-optičkog žirokompasa takođe mora biti horizontalno nivelisana. To nije direktno ostvarljivo, jer senzori nivoa horizonta ne mogu biti pričvršćeni za ovu virtuelnu ravan. Međutim, signali koji dolaze od senzora nivoa pričvršćenih za brod poznati su i jednaki su nuli kada je ravan vezana za brod horizontalna. Uz pomoć Ojlerovih uglova ovi signali mogu se matematički transformisati u virtuelnu prostorno orijentisanu ravan. Rezultati su isti kao kada bi se signali mjerili direktno. Uz pomoć ovako transformisanih signala mjenjaju se Ojlerovi uglovi, što uslovljava kreiranje virtuelne horizontalno nivelisane i prostorno orijentisane ravni.

\section{Funkcija traženja sjevera}

Kod klasičnog žirokompasa ravan rotacije glavne ose prostorno je orijentisana i okreće se u odnosu na Zemlju. Sje- verna strana žirosfere podizaće se ili spuštati ukoliko glavna osa sistema nema pravac geografskog sjevera. To uslovljava generisanje obrtnog momenta, što je direktna posljedica vertikalnog pomjeranja težišta. Pomjeranje težišta uslovljava pojavu precesije koja glavnu osu žiroskopa pomjera prema geografskom sjeveru. Ako se ostvari tačno proračunato prigušenje, navedeni proces će se smiriti kada se glavna osa poklopi sa sjeverom i horizontalnom ravni.

Kod fiber-optičkog žirokompasa inicijalna prostorno orijentisana ravan takođe se kreće u odnosu na Zemlju. Međutim, ovdje se ne radi o mehaničkom kretanju, već je izražena promjena Ojlerovih uglova u direkcionalnoj kosinusnoj matrici. Osa pravca sjevera u prostorno orijentisanoj ravni podiže se ili spušta toliko dugo dok se ne poklopi sa sjeverom. Kretanje koje prouzrokuje spuštanje i podizanje ravni registruje se preko transformisanih signala nivoa horizonta. Rezultantno odstupanje od horizontalnog položaja koristi se za promjenu Ojlerovih uglova, što dovodi do poravnavanja virtuelne prostorno orijentisane ravni sa sjeverom.

\section{Izlazni signali}

Kod konvencionalnog žirokompasa, nakon procesa smirivanja, može se mjeriti ugao između longitudinalne ose broda i geografskog sjevera. Ovaj ugao predstavlja kurs broda. Moguće je, takode, mjeriti i uglove koji se odnose na horizontalnu ravan (ljuljanje, posrtanje), ali to u praksi nije slučaj. Svi navedeni uglovi su između mehaničkih realnih elemenata. 
Kod fiber-optičkog žirokompasa pomenute procedure horizontalnog nivelisanja i traženja sjevera odvijaju se neprekidno i daju izlazne signale u formi Ojlerovih uglova. To nisu neposredno izmjereni uglovi, već matematički dobijeni uglovi koji su izvedeni na osnovu rotacije Zemlje. To su uglovi između ravni vezane za brod i matematički dobijene virtuelne ravni koja je horizontalno nivelisana, a orijentisana prema sjeveru. Iz ove informacije proračunavaju se uglovi koje brod (odnosno ravan vezana za njega) zaklapa sa horizontom (ljuljanje, posrtanje) i geografskim sjeverom (kurs).

\section{Karakteristike fiber-optičkih žirokompasa u skladu sa ISO 8728}

Međunarodnim standardom ISO 8728 [5] propisane su minimalne vrijednosti karakteristika koje moraju zadovo- ljiti svi žirokompasi. U tabeli su prikazane vrijednosti definisane navedenim standardom, a zatim redom odgovarajuće karakteristike fiber-optičkog žirokompasa SR 2100-Plath [6] i najmodernijih klasičnih žirokompasa STANDARD 20 ANCHUTZ i MERIDIAN-Brown [7].

Savremeni konvencionalni žirokompasi imaju manju dinamičku grešku pri određivanju kursa, ali je fiber-optički žirokompas daleko superiorniji po pitanju vremena smirivanja, što ga čini vrlo konkurentnim za primjenu kod ratnih brodova.

Fiber-optički žirokompas SR 2100 sastoji se od tri fizički odvojena dijela: senzorske jedinice, jedinice interfejsa i napajanja i jedinice za upravljanje i prikazivanje na displeju. Dimenzije jedinica su: $292 \times 340 \times 170 \mathrm{~mm}, 524 \times 341 \times 123$ $\mathrm{mm}$ i $288 \times 96 \times 55 \mathrm{~mm}$, a mase $11,5 \mathrm{~kg}$, $15 \mathrm{~kg}$ i $0,7 \mathrm{~kg}$, respektivno. Ukupna potrošnja (startovanje i normalan rad) žiro-

Karakteristike fiber-optičkih žirokompasa u skladu sa ISO 8728

\begin{tabular}{|c|c|c|c|c|}
\hline Karakteristika & ISO 8728 & SR 2100 & $\begin{array}{c}\text { STANDARD } \\
20\end{array}$ & MERIDIAN \\
\hline Vreme smirivanja & $<6 \mathrm{~h}$ & $\leq 30 \mathrm{~min}$ & $3 \mathrm{~h}$ & $45 \mathrm{~min}$ \\
\hline Kurs u tački smirivanja & $\pm 0,75^{\circ} \times \sec \varphi$ & $\pm 0,7^{\circ} \times \sec \varphi$ & $\pm 0,1^{\circ} \times \sec \varphi$ & $\pm 0,25^{\circ} \times \sec \varphi$ \\
\hline $\begin{array}{l}\text { Razlika proizvoljnog izmerenog kursa u tački smi- } \\
\text { rivanja i srednje vrednosti kursa u tački smirivanja }\end{array}$ & $\pm 0,25^{\circ} \times \sec \varphi$ & I & I & I \\
\hline Ponovljivost kursa od jednog do drugog uključenja & $\pm 0,25^{\circ} \times \sec \varphi$ & 1 & I & $\pm 0,25^{\circ} \times \sec \varphi$ \\
\hline $\begin{array}{l}\text { Vreme smirivanja u radnim uslovima: } \\
- \text { ljuljanje-posrtanje predstavlja prosto har- } \\
\text { monijsko kretanje sa periodom }(6-15) \mathrm{s} \text {, } \\
\text { maksimalnim uglom od } 5^{\circ} \text { i sa maksimalnim } \\
\text { horizontalnim ubrzanjem od } 0,22 \mathrm{~m} / \mathrm{s}^{2}\end{array}$ & $<6 \mathrm{~h}$ & $\leq 30 \mathrm{~min}$ & $3 \mathrm{~h}$ & $45 \mathrm{~min}$ \\
\hline Kurs u tački smirivanja pod opštim uslovima & $\pm 1^{\circ} \mathrm{x} \sec \varphi$ & $\pm 0,7^{\circ} \times \sec \varphi$ & $\pm 0,4^{\circ} \times \sec \varphi$ & $\pm 0,6^{\circ} 0 \times \sec \varphi$ \\
\hline Kurs nakon korekcije pri brzini od 20 čvorova & $\pm 0,25^{\circ} \sec \varphi$ & 1 & I & 1 \\
\hline Kurs pri promeni brzine od 20 čvorova & $\pm 2^{\circ}$ & / & I & l \\
\hline $\begin{array}{l}\text { Kurs nakon promene kursa od } 180^{\circ} \text { pri brzini } \\
\text { od } 20 \text { čvorova }\end{array}$ & $\pm 3^{\circ}$ & I & I & I \\
\hline $\begin{array}{l}\text { Kurs na Scorsby stolu pri uticaju posrtanja, lju- } \\
\text { ljanja i kretanja predstavljenih prostim harmo- } \\
\text { nijskim kretanjem sa periodom }(6-18) \mathrm{s} \text {, maksi- } \\
\text { malnim uglovima od } 20^{\circ}, 10^{\circ} \text { i } 50^{\circ} \text { i pri maksi- } \\
\text { malnom horizontalnom ubrzanju od } 1 \mathrm{~m} / \mathrm{s}^{2}\end{array}$ & $\pm 1^{\circ} \times \sec \varphi$ & $\pm 0,7^{\circ} \times \sec \varphi$ & $\pm 0,4^{\circ} \times \sec \varphi$ & $\pm 0,6^{\circ} 0 \times \sec \varphi$ \\
\hline
\end{tabular}

$\varphi$ - geografska širina,

$\sec \varphi=1 / \cos \varphi$ 
kompasa je $45 \mathrm{~W}$ (DC). Napajanje je $115 / 230$ VAC $50 / 60 \mathrm{~Hz}$ ili 24 VDC (18 $\mathrm{V}$ do $36 \mathrm{~V})$. Moguće je priključiti 12 analognih ponavljača, a na raspolaganju su dvije NMEA 1083 linije, dvije RS 422 linije, jedna linija NMEA 0183 FAST, jedna linija RS 422 SUPER FAST, dva izlaza $6 \mathrm{korak} / \mathrm{stepen,} \mathrm{tri} \mathrm{brzinska} \mathrm{ana-}$ logna signala $\pm 10 \mathrm{~V}$, jedan brzinski analogni signal 4 do $20 \mathrm{~mA}$ i jedna dvosmjerna linija HDLC.

Ako se navedene karakteristike uporede sa klasičnim žirokompasom SPERRY MK 37 VT, koji predstavlja industrijski standard, stanje je sljedeće:

MK 37 VT se sastoji od tri fizičke jedinice: osnovne jedinice, jedinice elektronike i uređaja za prikazivanje na displeju. Dimenzije jedinica su: $368 \times 325 \times 443$ $\mathrm{mm}, 528 \times 510 \times 258 \mathrm{~mm}$ i $288 \times 144 \times 42$ $\mathrm{mm}$, a mase $38 \mathrm{~kg}, 13 \mathrm{~kg}$ i $1,2 \mathrm{~kg}$, respektivno. Napajanje žirokompasa je 115/230 $\mathrm{VC} \pm 10 \%$ i 47 do $64 \mathrm{~Hz}$. Potrošnja iznosi 24 VDC@8 A. Izlazni signali su standardizovani i u saglasnosti su sa ISO 8728. Ukupna masa SR 2100 je 27,2 kg prema $52,2 \mathrm{~kg}$ mase MK 37. Potrošnja SR 2100 je $45 \mathrm{~W}$ prema $192 \mathrm{~W}$ potrošnje MK 37.

\section{Zaključak}

Novi fiber-optički žirokompas NAVIGAT 2100 prvi je potpuno elektronski „solid-state“ pomorski žirokompas sa visokom dinamičkom tačnošću i vrlo kratkim vremenom smirivanja. Namjenjen je za integrisane komandne mostove i vrlo brze brodove. Uređaj je vrlo pouzdan i sa malom mogućnošću da dođe do neispravnosti, jer ne posjeduje rotacione mehaničke elemente.

NAVIGAT 2100 daje podatke o kursu, uglu valjanja i posrtanja, i informaciju o brzini obrtanja oko sve tri ose. Ove karakteristike mu osiguravaju sigurnu primjenu kod ratnih brodova.

\section{Literatura:}

[1] Hallbauer, Hans-Diter: The First Fiber-Optic Gyrocompass, Plath Publication, Hamburg, 1998.

[2] Buschelberger, H. J.: The Fiber Optical Gyroscope, Plath Publication, Hamburg, 1997.

[3] Agilent Technologies: Lightwave Test and Measurement Catalog, Publ. No. 5980-8000E, USA, 2001.

[4] Gonda, S.; Seko, D.: Optoelektronika v voprosah i otvetah, Prevod sa japanskog na ruski jezik, Energoizdat, Lenjingrad, 1989.

[5] ISO 8728: Ships and marine technology - Marine gyrocompasses, Geneve, 1997.

[6] Kataloški podaci firme C.Plath za fiberoptički žirokompas SR (NAVIGAT) 2100, Hamburg, 1998.

[7] Unković, M.: Standardizacija metroloških karakteristika brodskih navigacionih žirokompasa, Kongres metrologa Jugoslavije, Zbornik radova na CD, Novi Sad, 2000. 
